Instytut Archeologii

Uniwersytet Mikołaja Kopernika w Toruniu

ul. Szosa Bydgoska 44/48, 87-100 Toruń

annadr@umk.pl

Anna Drązkowska

\title{
NAKRYCIA GŁOWY BISKUPÓW PRZEMYSKICH Z ARCHIKATEDRY PW. JANA CHRZCICIELA I WNIEBOWZIĘCIA NAJŚWIĘTSZEJ MARYI PANNY
}

Zarys treści. W artykule zaprezentowano nakrycia głowy wydobyte podczas badań w kryptach grobowych archikatedry przemyskiej. Stanowiły one wyposażenie pochówków biskupów ordynariuszy i sufraganów. Analizie poddano mirty, będące ważną częścią stroju pontyfikalnego i kalotki, które nie są szatą liturgiczną. Zwrócono uwagę na charakterystyczne cechy ich kroju i wykończenia. Na podstawie źródeł pisanych zaprezentowano je w szerszym kontekście symboliczno-kulturowym, zwracając uwagę na odmienną funkcję, jaką pełniły oba nakrycia głowy.

Słowa kluczowe: nakrycia głowy, mitra, kalotka, odzież pontyfikalna, archikatedra w Przemyślu.

W latach 2010-2015 w podziemiach archikatedry pw. Świętego Jana Chrzciciela i Wniebowzięcia NMP w Przemyślu prowadzano prace remontowe i adaptacyjne mające na celu przygotowanie krypt do ekspozycji muzealnej. W ich trakcie ustalono, że pod świątynią znajduje się 27 krypt różnej wielkości (Drążkowska 2014, s. 23). Odnaleziono w nich między innymi pochówki biskupów: pięciu ordynariuszy i pięciu pomocniczych; jednego nie udało się zidentyfikować. Ich szczątki spoczywały w drewnianych trumnach pokrytych jedwabnymi tkaninami. Badania autorki artykułu wykazały, że biskupów złożono do grobu w pełnym stroju pontyfikalnym i wraz z bielizną mieli na sobie 17 elementów ubioru.

W niniejszym tekście zaprezentowane zostaną nakrycia głowy, które znaleziono w trumnach: mitry i kalotki, zwane piuskami. Uwagę skupiono na tych częściach stroju, ponieważ w trakcie badań archeologicznych są stosunkowo rzadko odkrywane, a należą do bardzo istotnych i charakterystycznych detali noszonych przez biskupów. Mitry, określane również jako infuły, zachowały się 
przy szczątkach Józefa Tadeusza Kierskiego (1706-1783), Stanisława Wykowskiego (1700-1776), Franciszka Szembeka (1686-1728), Andrzeja Pruskiego (1682-1759), Michała Witosławskiego (1702-1769) oraz w grobie ziemnym biskupa o nieznanej tożsamości (ryc. 1).

Mitry są wysokimi nakryciami głowy o charakterystycznym kształcie i konstrukcji składającej się z dwóch ułożonych frontalnie trójkątnych tarcz wyciętych z tkaniny i połączonych z sobą wzdłuż dwóch boków do połowy ich długości. Usztywniano je tekturą, dzięki której unosiły się wysoko i utrzymywały swoją wysmukłą formę. Niezszyte ich części lekko rozchylały się, a wolną przestrzeń, która w tym miejscu powstawała, przesłaniano kawałkiem tkaniny. Z tyłu, na środku, do dolnego brzegu przyszywano dwie, stykające się wewnętrznymi krawędziami szarfy, rozszerzające się lekko ku dołowi. Spadały one swobodnie na plecy (Drążkowska 2014, s. 246-249).

Prezentowane mitry znaleziono w różnym stanie zachowania: cztery przetrwały w całości ${ }^{1}$, dwie kolejne tylko we fragmentach ${ }^{2}$. W przypadku zmumifikowanych ciał dwóch biskupów Józefa Tadeusza Kierskiego i Stanisława Wykowskiego, znajdowały się one nie na głowach, lecz na ornacie, nieco poniżej bioder (ryc. 1). Nie jest to typowe miejsce dla mitry, ponieważ na innych stanowiskach, na przykład w katedrze we Fromborku lub w kryptach u reformatów w Krakowie, nakrycia te założono zmarłym na głowy.

Dwie mitry z analizowanego zespołu uszyto specjalnie do grobu, miały krawędzie połączone ściegiem fastrygowym. O ich jednorazowym przeznaczeniu świadczy także brak tektury usztywniającej tarcze i materiału od góry zamykającego mitrę. Pozostałe nakrycia głowy, zanim trafiły do grobu, używane były podczas uroczystych mszy pontyfikalnych.

Wszystkie prezentowane tu mitry uszyto z drogich tkanin jedwabnych, ale ich tarcze są gładkie, bez haftowanych ozdób. Ze złotej lamy przygotowano infułę dla Franciszka Szembeka i biskupa o nieustalonej tożsamości, ze srebrnej dla Andrzeja Pruskiego. Z gładkiej, fioletowej tafty skrojono to nakrycie głowy dla Józefa Tadeusza Kierskiego (Drążkowska 2014, s. 247), z amarantowego rypsu natomiast dla Stanisława Wykowskiego (ryc. 1). Mitry podszyto od spodu jedwabnymi podszewkami w różnych kolorach: białym ${ }^{3}$, bordowym ${ }^{4}$ i amarantowym ${ }^{5}$.

\footnotetext{
${ }^{1}$ Mitry zachowane w całości: Stanisława Wykowskiego (wysokość $40 \mathrm{~cm}$, długość szarf $39 \mathrm{~cm}$ ), Franciszka Szembeka (wysokość $38 \mathrm{~cm}$, długość szarf $41 \mathrm{~cm}$ ), Józefa Tadeusza Kierskiego (wysokość 39,5 cm, długość szarf 39,5 cm), Andrzeja Pruskiego (wysokość $39 \mathrm{~cm}$, długość szarf 43,5 cm).

${ }^{2}$ Mitra we fragmentach: Michała Witosławskiego i biskupa o nieustalonej tożsamości.

${ }^{3}$ Mitra biskup Józefa Tadeusza Kierskiego.

${ }^{4}$ Mitra Stanisława Wykowskiego.

${ }^{5}$ Mitra Franciszka Szembeka i dla biskupa o nieustalonej tożsamości.
} 

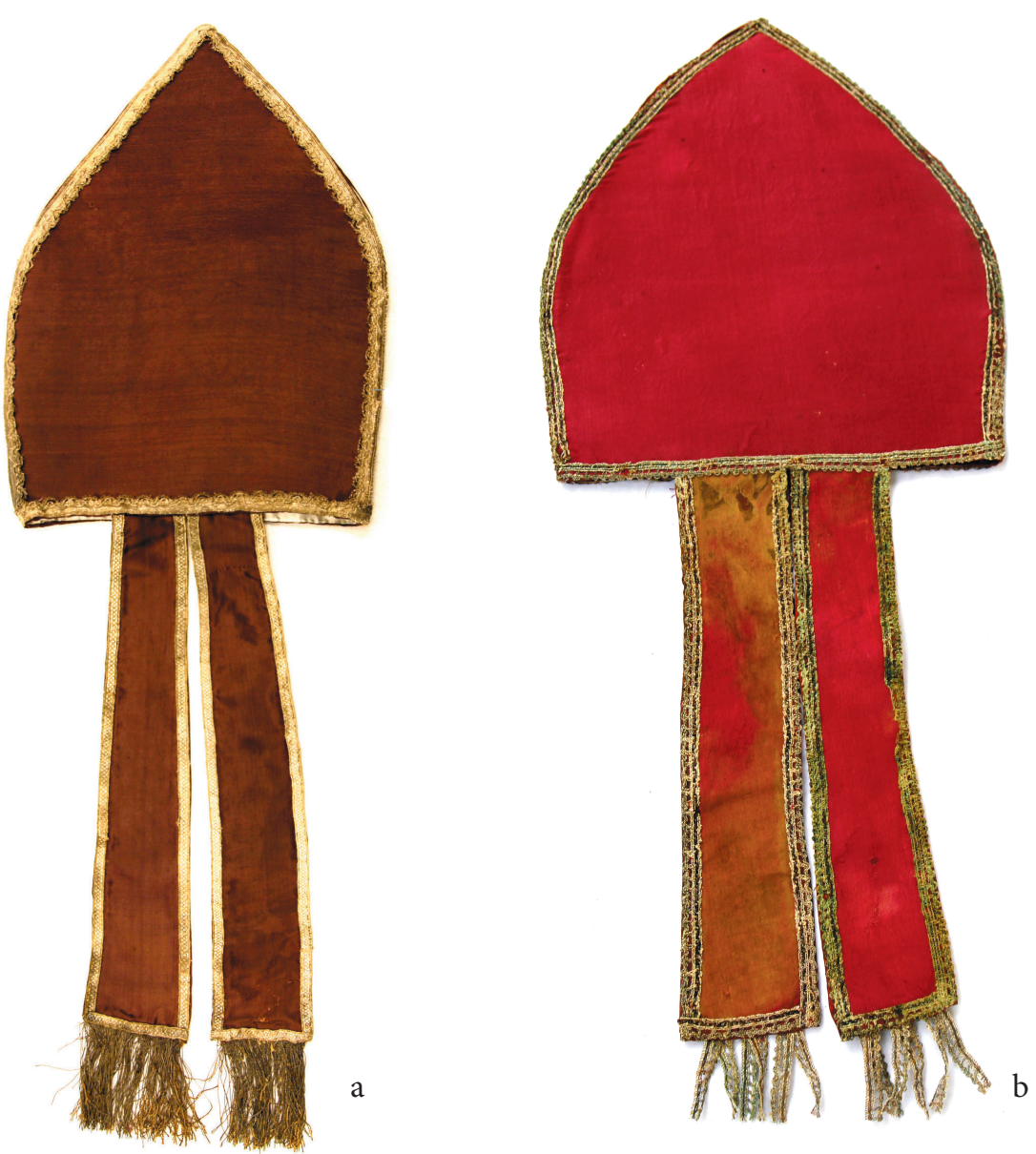

Ryc. 1. Przemyśl, archikatedra pw. Jana Chrzciciela i Wniebowzięcia Najświętszej Maryi Panny. a - mitra biskupa Józefa Tadeusza Kierskiego; b - mitra biskupa Stanisława Wykowskiego (fot. A. Drążkowska)

Fig. 1. Przemyśl, the archcathedral of St John the Baptist and the Assumption of the Blessed Virgin Mary. a - mitre of bishop Józef Tadeusz Kierski, b - mitre of bishop Stanisław Wykowski (photo by A. Drążkowska)

Przemyskie infuły mają skromne dekoracje, ponieważ tarcze i szarfy obszy to tylko wzdłuż krawędzi wąskimi galonami (szerokość od $0,7 \mathrm{~cm}$ do $1,5 \mathrm{~cm}^{6}$ ) z nici o metalowym oplocie. Szarfy niektórych z nich ${ }^{7}$ u dołu wykończono dodatkowo frędzlami ze skręconych nici z pozłacanej lamelki. Te delikatne, wiszące swo-

\footnotetext{
${ }^{6}$ Szerokości metalowych galonów: 0,7 cm na mitrze biskupa Andrzeja Pruskiego, 1,5 cm na mitrze Stanisława Wykowskiego, $1 \mathrm{~cm}$ na mitrze biskupa o nieustalonej tożsamości, 1,1 cm na mitrze biskupa Józefa Tadeusza Kierskiego.
}

${ }^{7}$ Frędzle zachowały się przy nakryciu głowy biskupa Józefa Tadeusza Kierskiego i biskupa o nieustalonej tożsamości. 
bodnie ozdoby poruszały się, przez co jeszcze bardziej połyskiwały i mieniły się złotym blaskiem, który kontrastował lub współgrał z kolorem mitry. Do infuły Stanisława Wykowskiego doszyto frędzle z wąskiej, ażurowej, pociętej na sześć krótkich kawałków tasiemki, tej samej, którą obszyto krawędzie ornatu, stuły, manipularza, tuniceli i dalmatyki (ryc. 1: b). Na jednej z szarf mitry Franciszka Szembeka znajduje się wyhaftowana pozłacaną nicią pusta tarcza herbowa (Drążkowska 2014, s. 250).

Mitra jest wyjątkowym nakryciem głowy, ponieważ jest swego rodzaju „duchową przyłbicą”, która ochrania i wspiera biskupa w walce z niewiernymi, chroni go też przed pokusami świata (Nowowiejski 1902, s. 397). Poza tym tylna tarcza symbolizuje Stary Testament, a przednia Nowy (Bogacka 2008, s. 235).

Mitra stanowi jeden z insygniów, które biskup otrzymywał podczas konsekracji. Konsekrator nakładając mitrę na głowę mówił: Imponimus, Domine, capiti huius Antistitis et agonistae Tui galeam munitionis et salutis, quatenus decorata facie et armato capite cornibus utriusque Testamenti terribilis appareat adversariis veritatis; et; Te ei largiente gratiam, impugnator eorum robustus existat, qui Moysis famuli Tui faciem ex Tui sermonis sermonis consortio decoratam lucidissimis Tuae charitati ac veritatis cornibus insignistis, et capiti Aaron Pontificis Tui tiaram imponi jussisti. Per Christum...(„Wkładamy, Panie, na głowę tego wodza i bojownika Tego przyłbicę obrony i zbawienia, aby z ozdobioną twarzą i uzbrojoną głową tarczami obydwóch Testamentów był strasznym dla przeciwników prawdy; aby mężnie się z nimi potykał za pomocą łaski Twojej, któryś twarz Mojżesza, sługi Twego wskutek przestawania z Tobą uczynił ozdobioną w świetlane łaski Twojej i prawdy rogi, i na głowę Arona arcykapłana Twego włożyć tiarę rozkazałeś. Przez Chrystusa Pana naszego. Amen"; Nowowiejski 1902, s. 397-398).

Podobnymi słowami modlił się biskup, gdy podczas przygotowań do mszy pontyfikalnej nakładano mu na głowę infułę: Mitram, Domine, et salutis galeam impone capiti meo: ut contra antiqui hostis, omniumque inimicorum meorum insidias inoffensus evadam (,Włóż na głowę mą, Panie infułę i przyłbicę zbawienia: abym wobec zasadzek szatana i wszystkich nieprzyjaciół moich pozostał bezpieczny"; Nowowiejski 1902, s. 398).

Mitra jest ważnym elementem stroju liturgicznego, ale kwestią sporną pozostaje okres wprowadzenia jej jako obowiązkowej szaty. Część badaczy uznaje, że pojawiła się już w czasach wczesnochrześcijańskich, jednak wówczas ponoć zakładano ją na głowę przesłoniętą chustą i miała wyglądać jak zawój ze złotą obręczą. W takiej formie przetrwała kilka wieków. Inni naukowcy wskazują, że zaczęto ją nosić dopiero w X stuleciu (Nowowiejski 1902, s. 381). Pod koniec tego okresu metalową obręcz zamieniono na tekstylną, bogato haftowaną opaskę, którą czasami zastępowało białe, płócienne nakrycie głowy. Długo trwało, zanim wykształciła się charakterystyczna dla nowożytnej infuły forma. Pod koniec XI wieku stała się podobna do rzymskiej mitry cornua (Nowowiejski 
1902, s. 385). W 1049 roku papież Leon IX nadał przywilej noszenia mitry rzymskiej arcybiskupowi Trewiru Eberhardowi i jego następcom (Nowowiejski 1902, s. 385; Braun 1907, s. 448; Bogacka 2008, s. 45; Drążkowska 2014, s. 250). Później był on nadawany innym biskupom, a od połowy kolejnego stulecia mitrę mogli już nosić wszyscy biskupi „naśladując książąt Kościoła, którzy otrzymali infułę, jako znak szczególniejszego wyróżnienia papiezkiego" (Nowowiejski 1902, s. 385). W XII wieku to nakrycie głowy składało się z dwóch symetrycznych, połączonych ze sobą części, nazywanych tarczami (cornua), podszewki i dwóch zwisających szarf (Bogacka 2008, s. 46). Wówczas zakładano ją w dwojaki sposób: tarcze były skierowane frontem lub na boki, jednak już od XIII wieku mitry noszono tylko z tarczami ustawionymi frontalnie (Pikulski 2002, s. 131). Z czasem wykształciły się ich trzy rodzaje: pretiosa, auriphrygiata i simplex (Nowowiejski 1902, s. 393). Różniły się między sobą barwą, gatunkiem tkaniny i ozdobami, które do nich przyszywano. Podwyższenie tarcz mitry nastąpiło w średniowieczu, a później, w XVI stuleciu, przyczyniło się do zwiększenia powierzchni, którą można było przeznaczyć na ozdoby. Najbardziej reprezentacyjna była mitra pretiosa, czyli drogocenna. Obszywano ją perłami i kolorowymi klejnotami. Ilość dekoracji zależała od biskupich funduszy i od panującej mody (Bogacka 2008, s. 166). Dla przykładu w baroku rozpowszechniły się infuły pokrywane bogatym haftem wykonanym przy użyciu złotych i srebrnych nici, a klejnoty stanowiły jedynie kosztowny dodatek uzupełniający kompozycję (Bogacka 2008, s. 255). Metalowe nici, układane gęsto, jedna obok drugiej, tworzyły na tarczy wzorzyste, połyskujące tło. Dodatkowo wzmacniały i usztywniały konstrukcję, a także wraz z doszytymi perłami i klejnotami powodowały, że mitry były bardzo ciężkie, przez co nadmiernie obciążały głowę i wymuszały odpowiedni sposób utrzymywania w pionie całej sylwetki. Wpływały także na dość powolne poruszanie się biskupów ubranych w strój pontyfikalny. Gdy kosztowności było zbyt dużo, w środek infuły, między tkaniny, wszywano długie żelazne blaszki, które miały wzmocnić konstrukcję, utrzymać formę i zapobiec deformowaniu tarcz pod wpływem ciężaru (Nowowiejski 1902, s. 392).

Kolejna mitra - auriphrygiata - przygotowywana była z drogocennych tkanin lansowanych złotem lub haftowanych. Nie doszywano do niej jednak kamieni szlachetnych. Zasady używania, między innymi tej mitry, zawarto w Ordo Romanus z XIV wieku: „Mitra aurifrigiata [!] nie będzie używana przez Kościół rzymski od Adwentu aż do Narodzenia Pańskiego, oprócz tego, gdy papież będzie używał [jej] w niedzielę Gaudete, ani od Siedemdziesiątnicy [trzeciej niedzieli przed Wielkim Postem] aż do V dnia [Piątku] Wielkiego Tygodnia, z wyjątkiem, gdy papież będzie używał [jej] w IV niedzielę Wielkiego Postu [Czterdziestnicę], podczas śpiewu »Raduj się Jeruzalem«, także nie będzie używał jej w żadne wigilie, które jak w poście się celebruje, ani w suche dni [dni kwartalne], ani podczas modlitw za zmarłych" (Bogacka 2008, s. 48). 
Mitra simplex była znacznie skromniejsza, wykonana $\mathrm{z}$ białego jedwabiu lub płótna. Biskup zakładał ją do odprawiania liturgii pogrzebowej i nosił podczas nabożeństw w Wielki Piątek. W zbiorach muzealnych zachowało się niewiele tych nakryć głowy, dlatego tak istotnym znaleziskiem są mitry z archikatedry przemyskiej. Ze względu na prostotę ich wykonania zaklasyfikować je można jako mitra simplex.

Kolejnym nakryciem głowy odnalezionym w trumnach ze szczątkami biskupów są cztery małe czapeczki o prostym kroju, zwane kalotkami ${ }^{8}$. Wyglądają jak obecnie noszone przez biskupów piuski ${ }^{9}$. Dwie uszyto z jedwabnego rypsu w kolorze amarantowo-fioletowym z ośmiu jednakowej wielkości klinów, dzięki którym idealnie dopasowywały się do owalnego kształtu głowy. Podszyto je od spodu skórą irchową w kolorze écru, która usztywniała konstrukcję. Jedną z kalotek, należącą do biskupa Stanisława Wykowskiego, wzdłuż łączonych krawędzi przeszyto podwójnym, ozdobnym ściegiem - stębnówką (ryc. 2: a). Dwie kolejne czapeczki mają odmienny krój. Należąca do biskupa Franciszka Szembeka, przygotowana z czterech klinów z amarantowego rypsu, różni się wyglądem od pozostałych (ryc. 2: b). Jej zewnętrzne krawędzie wyprofilowano dzięki doszytym półokrągłym paskom. Nieco inny krój czapeczki zmieniał jej sposób noszenia, ponieważ nie leżała już na czubku głowy, lecz schodziła niżej - na skronie.

W analizowanym zespole na uwagę zasługuje kalotka odnaleziona poza pochówkiem, w przemieszanym materiale pod łukiem tęczowym (ryc. 2: c). Uszyto ją z czterech szerszych klinów z jedwabnego atłasu w kolorze brązowym. Na czubku głowy, w miejscu, gdzie zbiegały się kliny, wszy to wstawkę z koronki klockowej z małym krzyżem na środku. Ten model nakrycia głowy wydaje się być starszy od pozostałych, może pochodzić z XVII wieku. Kalotka w odróżnieniu od mitry nie jest szatą liturgiczną, dlatego nie ma formuły benedykcji - specjalniej modlitwy, która byłaby odmawiana podczas jej zakładania.

Istnieje kilka koncepcji na temat pojawienia się tej czapeczki i nadal pozostaje to kwestią sporną. Ksiądz Antoni Julian Nowowiejski uważa, że znane były pod nazwą pileus już w XI wieku i przeznaczone dla dygnitarzy Kościoła (Nowowiejski 1902, s. 134). W XIII wieku taki przywilej otrzymali również opaci św. Augusta w Canterbury (Nowowiejski 1902, s. 135). Joseph Braun na podstawie przedstawień ikonograficznych twierdzi natomiast, że to nakrycie głowy nie było jeszcze znane w XII wieku, ponieważ nie występuje na wizerunkach papieży i biskupów. Według niego pojawiło się po raz pierwszy dopiero w połowie XIV stulecia, a w XV wieku było już powszechnie używane i zakładane

${ }^{8}$ Odnaleziono je w trumnach Stanisława Wykowskiego, Andrzeja Pruskiego, Franciszka Szembeka; kolejna kalotka leżała w przemieszanym materiale w krypcie centralnej pod łukiem tęczowym.

${ }^{9}$ Nazwa pochodzi od imienia papieża Piusa IX (ur. 13 maja 1792 w Senigallii). Jego pontyfikat trwał od 16 czerwca 1846 roku do śmierci 7 lutego 1878 roku. 

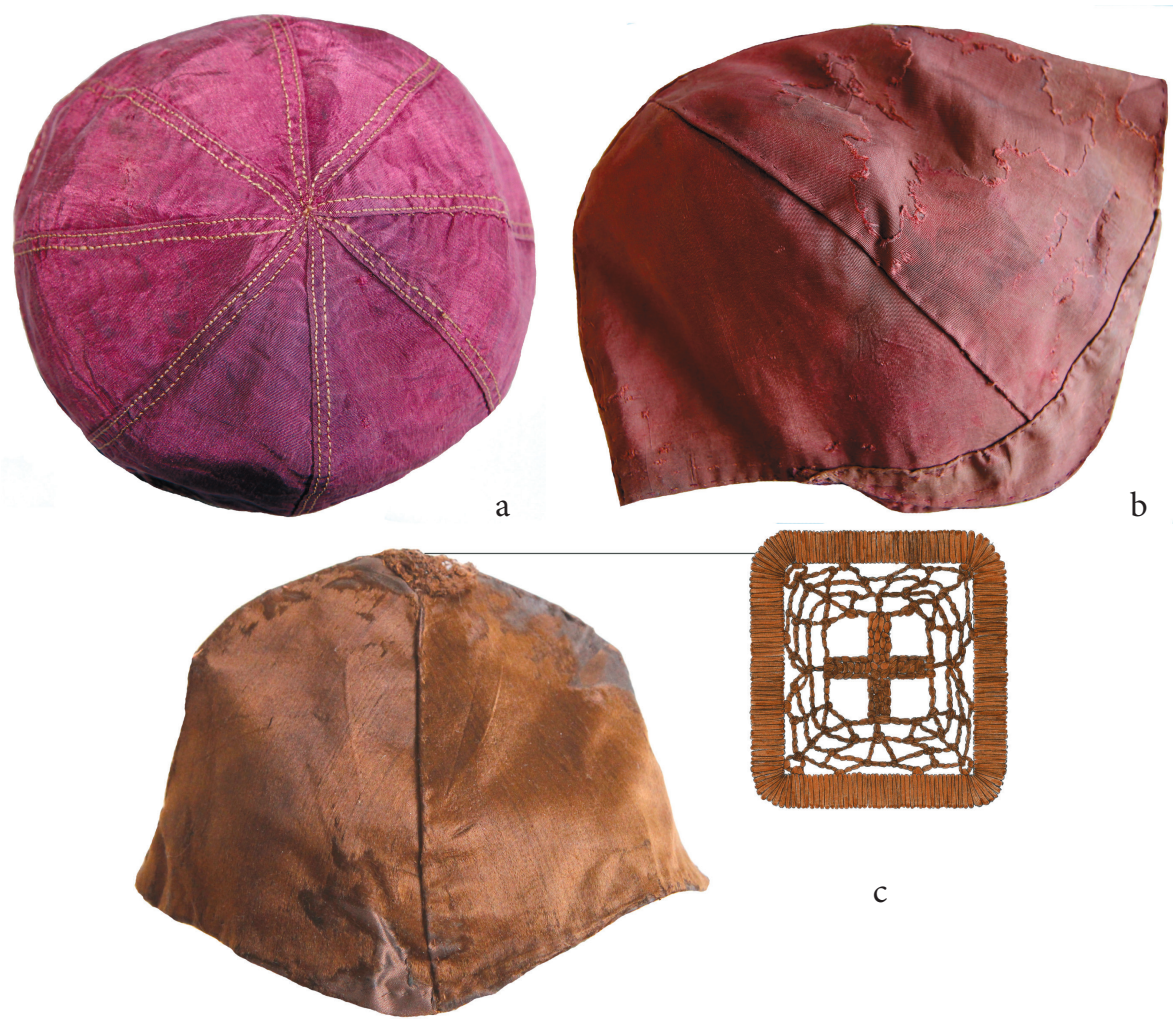

C

Ryc. 2. Przemyśl, archikatedra pw. Jana Chrzciciela i Wniebowzięcia Najświętszej Maryi Panny. a - kalotka biskupa Stanisława Wykowskiego; b - kalotka biskupa Franciszka Szembeka; c - kalotka odnaleziona poza pochówkiem w przemieszanym materiale, ozdobiona wstawką z koronki (fot. A. Drążkowska)

Fig. 2. Przemyśl, the archcathedral of St John the Baptist and the Assumption of the Blessed Virgin Mary. a - calotte of bishop Stanisław Wykowski; b - calotte of bishop Franciszek Szembek; c - calotte found outside the burial in mixed material, decorated with a lace insert (photo by A. Drążkowska)

również razem z mitrą (Braun 1907, s. 509). Dzięki temu chroniło głowę przed jej ciężarem i krawędziami, które mogły boleśnie ocierać skronie i czoło biskupa (ryc. 3). Na ziemiach polskich obecność pileusa została potwierdzona źródłami ikonograficznymi dopiero w XVI wieku. Na wcześniejszych przedstawieniach to nakrycie głowy nie występuje. Pileus na początku nie przypominał małej kopulastej czapeczki noszonej na czubku głowy. Jego dolna krawędź z przodu przesłaniała część czoła, a po bokach zakrywała skronie. Przez długi czas jego noszenie nie było obowiązkowe i przez to również niezbędne. Nie można wskazać, kiedy zmienił się wygląd pileusa i kiedy przekształcił się w małą kalotkę, zwaną później piuską (Drążkowska 2014, s. 286). Prawdopodobnie mogło to 
Ryc. 3. Arcybiskup w stroju pontyfikalnym z mitrą ozdobioną klejnotami, spod której wystaje profilowana krawędź pileusa, (Arcybiskup Wincenty z Niałka - miniatura Stanisława Samostrzelnika, Żywoty arcybiskupów gnieźnieńskich Jana Długosza, 1530-1535, Biblioteka Narodowa w Warszawie)

Fig. 3. Archbishop in pontifical dress with mitre decorated with jewels, under which a profiled edge of a pileus protrudes (Archbishop Wincenty of Niałek - miniature by Stanisław Samostrzelnik, Żywoty arcybiskupów gnieźnieńskich Jana Długosza, 1530-1535, National Library in Warsaw)

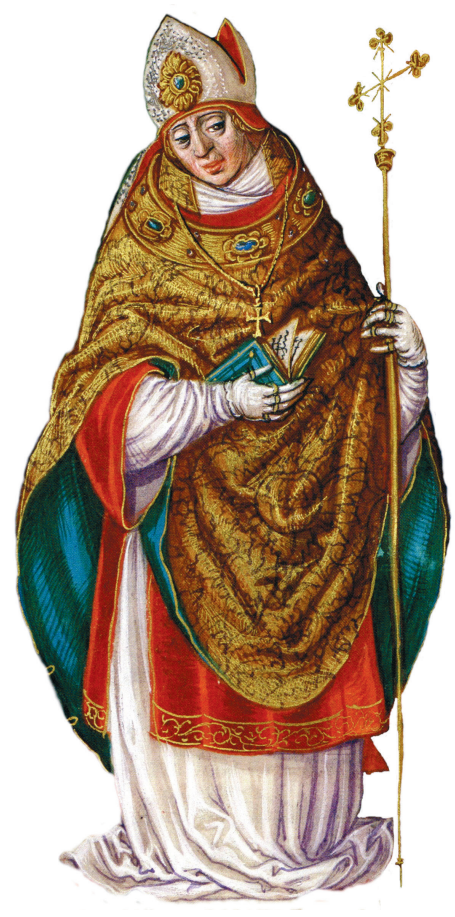

nastąpić w wieku XVII, ponieważ w XVIII stuleciu te nakrycia głowy mają już formę małych kopułek.

Przemyskie znaleziska należą do bardzo interesujących i na razie unikatowych, ponieważ do tej pory pileusy nie zostały odnalezione w takcie badań archeologicznych, a nakrycie głowy Franciszka Szembeka właśnie je przypomina. Mitry również odnaleziono w kryptach przemyskich po raz pierwszy, kolejne znaleziska z innych stanowisk są już wtórne. Ich obecność potwierdza, że wyposażano w nie biskupów zwyczajowo, przestrzegając rubryk zawartych w Ceremoniale Episcoporum ${ }^{10}$ z 1633 roku, w którym czytamy: „Gdy Biskup odda ducha Stwórcy, [...] Po wymyciu ciała i wytarciu tzw. zaufani domownicy biskupa albo inni spośród duchowieństwa i z mistrzem ceremonii ubierają owego [biskupa] najpierw w osobiste szaty aż do rokiety, a następnie w szaty sakralne, w które był wcześniej Biskup ubierany za życia, gdy sprawował w sposób uroczysty mszę, to jest, pończochy, sandały, humerał, albę, cingulum, stułę, manipularz, krzyż pektoralny, tunicellę, dalmatykę. Do tego są rękawiczki Biskupie, ornat w kolorze fioletowym i pierścień Biskupi, także mitra prosta" (Caeremoniale Episcoporum

\footnotetext{
${ }^{10}$ Księga ta przechowywana jest w skarbcu przemyskiej katedry. Ceremoniał był skierowany do biskupów i mistrzów ceremonii liturgicznych oraz osób asystujących biskupowi w czasie sprawowania liturgii. Dotyczył także ważniejszych wydarzeń w życiu biskupa oraz uroczystych aktów związanych z jego posługą.
} 
1633, s. 356). W cytowanej powyżej księdze nie ma jednak żadnej wzmianki ani o pileusie, ani o kalotce, ponieważ te nakrycia głowy nie należały do przyjętego kanonu odzieży, w której składano do grobu biskupów. Wyjaśnia to ich sporadyczne występowanie w pochówkach.

\section{Bibliografia}

\section{Źródła}

Ceremoniale Episcoporum, 1633, Ceremoniale Episcoporum Klementis VIII, Paris.

\section{Literatura}

Bogacka K., 2008, Insygnia biskupie w Polsce. Pierścień, pektoral, infuła XIXVIII w., Warszawa.

Braun J., 1907, Die Liturgische Gewandung im Occident und Orient nach Ursprung und Entwiclung. Verwendung und Symbolik, Freiburg im Breisgau.

Drążkowska A., 2014, Odzież i insygnia grobowe biskupów przemyskich obrzadku tacińskiego, Toruń.

Nowowiejski A.J., 1902, Wykład liturgji kościoła katolickiego, t. 2, Warszawa.

Pikulski A., 2002, Mitra. Studium historyczno-artystyczne, Lublin.

\section{HEADDRESS OF PRZEMYŚL BISHOPS FROM THE ARCHCATHE- DRAL OF ST JOHN THE BAPTIST AND THE ASSUMPTION OF THE BLESSED VIRGIN MARY}

Keywords: headdress, mitre, calotte, pontifical clothing, archcathedral in Przemyśl.

\section{Summary}

The article presents the headdress found during the research conducted in 2012-2015 in the crypts of the Przemyśl archcathedral. They were furnishings of burials of ordinary and suffragan bishops. There were analysed mitres, which are an important part of the pontifical attire, and calottes, which are not liturgical vestments. Both headdresses are exceptional finds because they are found relatively rarely during archaeological research. Although they are headdress typical of bishops, they differ significantly in form and purpose, which was demonstrated in the article. Based on written sources, the mitre was presented in a broader symbolic and cultural context, recalling the prayers that were said during the consecration and during 
preparation for the pontifical mass, when the mitre was placed on the bishop's head. Its appearance was discussed, paying attention to the characteristic features of the cut and finish, which made it possible to distinguish mitre: pretiosa, auriphrygiata and simplex. The way of wearing it was also indicated and the changes in its form observed over the centuries. The article also highlights the modifications in the appearance of the calotte. The Przemyśl finds allowed to capture various forms of this headdress and the transition stage between the calotte typical of the $16^{\text {th }}$ century and a fully shaped one made of several equal wedges. 